\title{
On comparing the performance of voltage source converters based D-STATCOM for voltage sag mitigation
}

\begin{abstract}
This paper studies the utilization of PWM voltage source converters in Distribution Static Synchronous Compensator (D-STATCOM) for voltage sag mitigation. Three different voltage source converter topologies based D-STATCOM; namely the two level, three level neutral point clamped and the three level flying capacitor are investigated and compared. The comparison is drawn based on harmonic profile, response time and the steady state time of the point of common coupling voltage for different VSCs based D-STATCOM. The investigation is carried out using MATLAB-SIMULINK Power System Blockset for different operating points and a comparison between the different topologies is provided.
\end{abstract}

Keyword: D-STATCOM; PWM voltage source converter; Voltage sag mitigation 